\title{
The order of recall and the recall of order
}

\author{
ROSAMOND GIANUTSOS \\ Adelphi University, Garden City, Long Island, New York 11590
}

\begin{abstract}
Four experiments are described. The first three lend support to the assertion that retrieval from short-term storage (STS) is improved, possibly to a maximum, if items are recalled in their originally presented order. In the fourth experiment a modified recall condition was introduced in which written position of recall reflected order information. Although the subject was not constrained to recall the items in order under this modified recall condition, both item and order retention increased in comparison to both free and serial recall conditions. Within the theoretical framework adopted, the results indicate that retrieval from STS is improved by recalling in order; while long-term storage (LTS) is reduced by the constraint to recall in order. However, LTS is increased by the retention of order information when recalling in order is not required.
\end{abstract}

Comparison of free and serial recall is illuminating. On the one hand, free recall has been used to advantage by Glanzer (1972) and others to study the effects of variables on long- and short-term storage (LTS and STS). A postlist reading task imposed between list presentation and recall is very effective in eliminating the STS (recency) effect (Glanzer, Gianutsos, \& Dubin, 1969) and, therefore, permits the methodological isolation of STS and LTS components. This model operationally defines LTS by insertion of a postlist reading task designed to displace the to-be-recalled items from STS. Postman (1975) has been sharply critical of what he views as the circularity of this logic since it requires the assumption, or, to use Postman's term, "faith," that recall following a sufficiently long postlist task reflects LTS only. Specifically, the assumption is that similar items serve as displacers of items at the STS level. It is not necessary to make any assumptions as to the effectiveness of dissimilar items as displacers, which Postman rightly doubts.

Generally, Postman (1975) is concerned that "the multiplicity and complexity of hypothetical mechanisms are outdistancing the observable facts" (p. 294). Sharing his concern about the reification of constructs, it should be noted that, although the present discussion is couched in terms of "stores" and "components," these are inferred processes and not things.

Returning to the present analysis, the formula for computing and separating STS and LTS contributions

An earlier version of this paper was presented to the Eastern Verbal Investigators' League meeting in New York, October 1972. Experiment I was presented to the Eastern Psychological Association in April 1972. Experiment III was presented to the Eastern Psychological Association in April 1973 by the author and Mitchell Foster. The author is grateful to Ellen Palgi for extensive help in Experiments I, II, and IV; John Chan for assistance in Experiments I and IV; Mitchell Foster for carrying out Experiment III; and Judith Orasanu for providing the basic idea for Experiment II. Leslie Packer, John Gianutsos, Carol Razel, Micha Razel, and Doris Aaronson kindly reviewed earlier versions. Mailing address: Department of Psychology, Adelphi University, Garden City, New York 11530. is based on Raymond (1969) and is identical to that of Waugh and Norman (1965), except that Waugh and Norman estimated LTS recall from the middle positions of a list and did not utilize a postlist task. Various other authors have adopted the Waugh and Norman approach (viz., Craik \& Levy, 1970; Glanzer, 1972), and it is in general use. Approaches to the problem of STS and LTS differentiation based on different assumptions and procedures than those adopted here have been proposed (Craik, 1968; Tulving \& Colotla, 1970). However, the operational Raymond (1969) definition has the advantage that it can be generalized to serial and other kinds of recall tasks.

On the other hand, ordered (serial) recall, unlike free recall, involves recalling order information which is inherent in language use. There are disadvantages with serial recall, however. Typically, LTS and STS contributions are not differentiated. This disadvantage may be remedied by the use of a procedure, such as a postlist reading task, which would eliminate STS but leave LTS unaffected.

An even more significant problem with serial recall arises from a basic confounding between the recall of items in their originally presented order (serial recall) and the recall of order information. Knowing the presentation order of to-be-recalled items is only part of what is involved in reproducing the sequence in order. Knowing the order is a necessary, but not sufficient, condition for using it, and serial recall involves more than retention of input order information. It also involves sequencing the output (recall). As will be demonstrated in the fourth experiment, in evaluating the retention of order information, it may be that serial recall is not the best procedure to use. A more sensitive measure of retention of order information can be achieved by not constraining the subject to recall in order.

The distinction between order information and the recall of items in order will be related to the two-storage process model. and the following conclusions drawn: 
(1) Retrieval from STS is improved by recalling in order; (2) for LTS it is the instruction to retain order information which improves recall.

\section{EXPERIMENT I}

The first experiment was carried out to see whether recall from STS could be improved by varying the order of recall. Much evidence (Gianutsos, 1970; Posner, 1964; Tulving \& Arbuckle, 1963) exists to support the hypothesis that the amount a subject recalls depends on the order in which items are to be recalled. The contention is that the act of recalling old items has the effect of displacing information from STS in much the same manner that taking in additional list items does. Put another way, input and output processing have similarly interfering effects. Although it is assumed, with Glanzer et al. (1969) and Shiffrin (1970), that inputting additional similar items is the major process by which items are displaced from STS, additional displacement occurs merely by verbalizing an item, whether or not the item verbalization occurs during input or recall.

Accordingly, the most efficient strategy for retrieving items from STS is to avoid their displacement prior to recall. An item which has been in the store longest is assumed to be most vulnerable. Therefore, the oldest item is the one which should be recalled first. In other words, if, at the end of a 12-word list, the 9th, 10th, 11 th, and 12th words are in STS, then the 9th word should be recalled first. If some other word is recalled first, as in backward recall, then the ninth word may be displaced out of STS without ever having been recalled. In the present experiment a technique was devised to manipulate the order of recall within the range of STS.

\footnotetext{
Method

Subjects. One hundred native English speaking Adelphi University undergraduates participated in this experiment. They earned extra credit for their introductory psychology course. The same source was used for all the succeeding experiments.

Procedure. Each subject was shown 12 lists of 12 highfrequency (AA, Thorndike-Lorge) monosyllabic nouns on a memory drum at a rate of 1 word/sec. Subjects were instructed to read the words aloud during presentation and to say them as they wrote them in the 1-min recall interval. A randomly determined half of the lists were followed by a postlist reading task. In this task, six additional words of the same kind, colored yellow, were to be read but not recalled. Comparison of the recall of these lists with the recall of lists with no postlist reading task permitted differentiation of STS and LTS contributions (Glanzer et al., 1969).

Subjects were randomly assigned to one of five instruction groups. A control group was given free recall instructions. The remaining four groups, respectively, had the third, fourth, fifth, or sixth word from the end of the list underlined with a blue marker. Subjects were instructed to begin their recall with this "blue" word and recall to the end of the list in order. Having recalled to the end of the list in this manner, they were to engage in free recall for the remaining list items.
}

Table 1 Orders of Recall in Experiment I

\begin{tabular}{|c|c|c|c|}
\hline \multirow[b]{2}{*}{$\begin{array}{l}\text { Postlist } \\
\text { Task }\end{array}$} & \multirow{2}{*}{$\begin{array}{c}\text { Instruction } \\
\text { Cue Position } \\
\text { (k) }\end{array}$} & \multicolumn{2}{|c|}{ Proportion } \\
\hline & & $\begin{array}{l}\text { Recall Starting } \\
\text { at Word } k\end{array}$ & $\begin{array}{l}\text { Ordered Recall } \\
\text { of Last k Words }\end{array}$ \\
\hline No Task & $\begin{array}{l}3 \\
4 \\
5 \\
6\end{array}$ & $\begin{array}{l}.98 \\
.94 \\
.86 \\
.78\end{array}$ & $\begin{array}{l}.94 \\
.69 \\
.27 \\
.02\end{array}$ \\
\hline Task & $\begin{array}{l}3 \\
4 \\
5 \\
6\end{array}$ & $\begin{array}{l}.53 \\
.45 \\
.61 \\
.52\end{array}$ & $\begin{array}{l}.09 \\
.02 \\
.00 \\
.00\end{array}$ \\
\hline
\end{tabular}

\section{Results}

The first column of data in Table 1 summarizes the proportions of trials in which subjects successfully began their recall with the cue word underlined in blue in the four experimental conditions, as a function of postlist task and cue position in the list. As can be seen, with no postlist task the proportion of correct starts successively decreased from almost $100 \%$ to approximately $75 \%$ as the cue position shifted further back into the list (i.e., from third from the end to sixth from the end). With a postlist task, subjects began their recall with the appropriate cue approximately $50 \%$ of the time, but there was no consistent relationship between proportion correct and cue position. The free recall control group (not shown) did not spontaneously recall in line with the instructions for the four experimental groups. The overwhelming favorite starting point was the last word from which recall was initiated $46 \%$ of the time.

Table 1 also shows the proportion of lists on which the instructions were followed completely, i.e., the subject began with the correct (cue) word and recalled all successive words in order. Without a postlist task, subjects followed instructions rather well when starting three or four words back. As the cue position shifted further into the list, however, performance fell sharply. With a postlist task, subjects were not able to execute the instructions completely, despite the fact that $50 \%$ of the time they started with the correct word. In free recall, the proportions of lists on which ordered recall was observed from three, four, five, or six words back were $.05, .02, .00$, and .00 , respectively. Clearly, then, there is virtually no spontaneous adoption of ordered recall strategies for outputting the end-of-list items.

Turning now to the recall data, the contribution of LTS is shown by the proportion of items recalled from the lists followed by a postlist task, since the postlist task was to eliminate any STS effects. Two conclusions may be drawn from the LTS serial position curves, as shown in Figure 1: (1) Marking a word and instructing a subject to use it to begin recall increased the likelihood of the marked item being coded into LTS, a kind of von Restorff effect. (2) Otherwise, no major effects were 


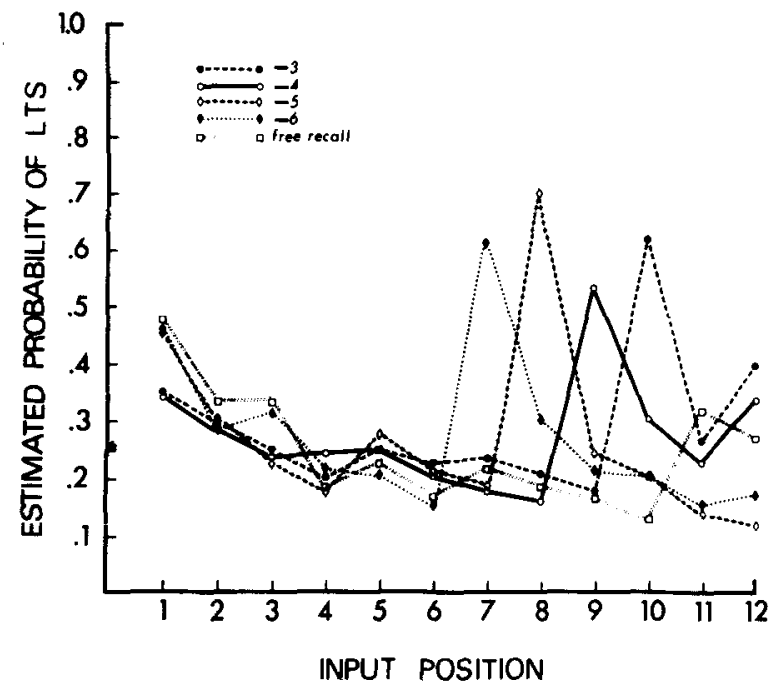

Figure 1. Serial position curves for LTS item recall in Experiment I. All lists were followed by a postlist reading task to eliminate STS.

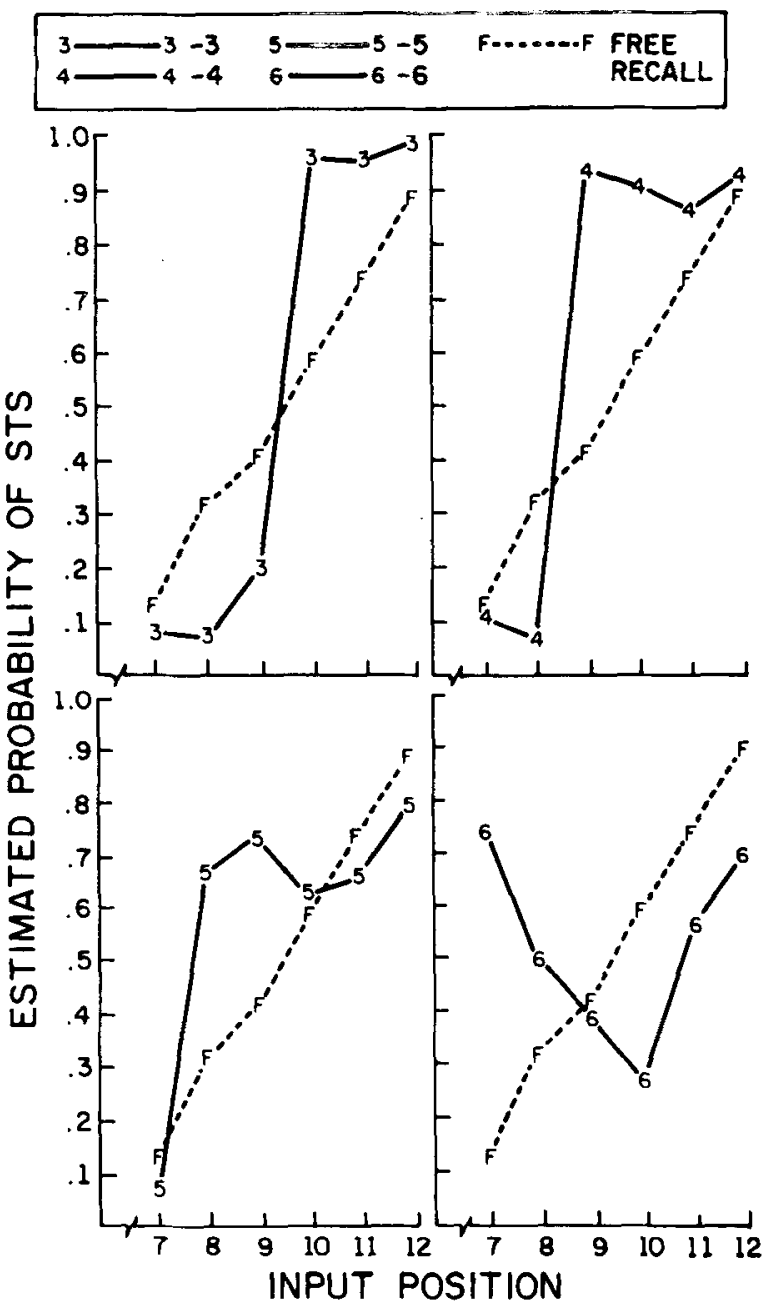

Figure 2. Serial position curves for STS item recall, estimated by the Raymond (1969) procedure, in Experiment $I$. Only the last half of each list is shown, since STS is assumed to be limited to that portion of the list. Each experimental condition is compared to a free recall control. seen in the LTS component corresponding to the five groups. In this and in subsequent experiments, analyses of variance were conducted on the recall data. The .05 level of significance was used throughout for all tests and only $F$ s whose $p$ values were less than or equal to .05 are reported. For the LTS data there were no significant effects of the subject groups in the first half of the lists-prior to the direct effects of the different groupsnor any interaction of Groups by Input Position.

The STS effects of the five groups appear large and clear-cut, both in the no-postlist-task serial position curves (not shown) and in the curves of STS (Figure 2) estimated by the Raymond (1969) procedure. Analysis of variance on the recall of the lists with no postlist task show significant effects of both treatment Groups $[\mathrm{F}(4,95)=4.46, \mathrm{MSe}=1.73]$, Input Position $[\mathrm{F}(5,385)=101.45, \mathrm{MSe}=1.18]$, and their interaction $[F(20,475)=35.14, M S e=1.18]$. Consistent with these tests, the STS curves in Figure 2 show dramatic and systematic increases in the STS component when recall was forward ordered from a marked point toward the end of the list. Summing the proportion recalled from STS for the last six positions gave the following estimates of the number of words recalled from STS: 3.31 , $3.81,3.52,3.16,3.02$ for the third, fourth, fifth, sixth from the end, and free recall, respectively. These estimates, together with Figure 2, show that for groups of subjects the greatest overall improvement in STS recall is obtained by beginning recall four words back. Beginning further back results in an embedded serial position curve, much as would be observed with serial recall. However, there is a diminishing gain in overall STS recall.

\section{Discussion}

The results confirm the importance of starting place and order of output in determining how much is ultimately recalled from STS. These findings, together with the theorized displacement mechanism of STS forgetting, lead one to expect that any experimental procedure which induces forward-ordered recall within the span of STS [approximately four words (Craik, 1968)] will show improved STS recall. Temporal (rhythmical) grouping is such a procedure. Gianutsos (1972) showed that, when lists were presented in temporal groups of three words, words were recalled in order within the last two groups, starting with the last group, and the STS component was substantially increased. The present view is that techniques, such as temporal grouping or the present procedure, improve retrieval from STS and do not affect LTS. It is argued here that these techniques simply increase the likelihood that what is in STS will be retrieved before being displaced by the act of recalling other items. Indeed, in accordance with a review by Glanzer (1972), the suggestion is that the storage capacity of STS is immutable.

An alternate, and contradictory, hypothesis-namely, that the storage capacity of STS is increased-is not completely ruled out by these data. As suggested by the 
findings of Watkins and Watkins (1974), it could be that when the subject encounters the cue which marks where to begin recall (during list presentation), processing is adjusted. This adjustment could have the effect of expanding STS to hold the remainder of the list. While this hypothesis contradicts the fairly well-supported view that STS is immutable, it is important that, as a logical possibility, it be tested.

\section{EXPERIMENT II}

To test this "improved storage" hypothesis, it is necessary to study recall under conditions in which the subject does not know the retrieval pattern to be used ahead of time, or during list presentation. Along these lines, an experiment similar to the preceding one was performed.

\section{Method \\ Subjects. Thirty students from the same source as in Experi- ment I participated. \\ Procedure. Each subject was shown 16 lists of -words. Half of the list included a postlist reading task, exactly as in Experi- ment I. There was a word from the main list to cue recall at the end of each list (following the postlist words, if any). Subjects were instructed to begin recall with this word and to continue recalling in order to the end of the list. Then they recalled as many of the other words as they could remember. The cue word was assigned randomly from the first, sixth from the last (7th), fourth from the last (9th), or last (12th) input position. The first case is like serial recall, while the last case is like free recall. In contrast to Experiment $I$, both variables (probe position and postlist task) were varied within subjects. This design was used to prevent the subject from being able to guess which word was to be the probe word.}

\section{Results}

Again the Raymond (1969) procedure was used to isolate the STS and LTS components. The results are shown in Figure 3, the left panel of which shows LTS recall and the right STS recall. In all cases, the "probe last" condition, which is closest to free recall, is compared with conditions in which the probes were in other positions. Separate analyses of variance were done on the recall data for lists with and without a postlist task. Input Positions 1, 7,9, and 12, which were used as probes in some conditions, were excluded from the analyses. In the first half of the list, there were reliable effects of Input Position $[F(4,116)=4.49, \mathrm{MSe}=.34]$ and Cue Condition $[\mathrm{F}(3,87)=5.53, \mathrm{MSe}=.37]$. These reflect the primacy peak and a reduction in recall at the beginning for the "probe first" condition. Neither effect is unusual or of interest here. No reliable effects were observed in the second half of the list when there was a postlist task. Overall, therefore, there were no important LTS effects. Without a postlist task, in the second half of the list (where STS effects would appear), the effects of both Condition and Input Position were significant $[\mathrm{F}(3,87)=5.22, \mathrm{MSe}=.39$ and $\mathrm{F}(2,58)=$ $32.72, \mathrm{MSe}=.47$, respectively] .

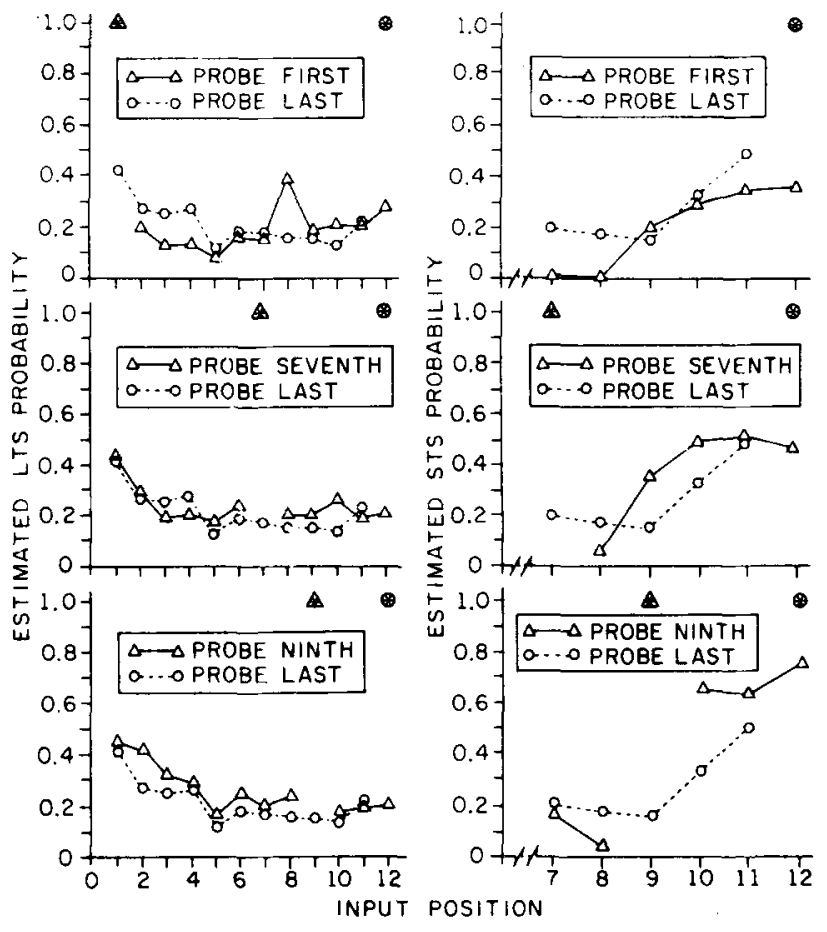

Figure 3. Serial position curves for LTS (left) and STS (right) item recall in Experiment II. STS recall was estimated by the Raymond (1969) procedure. The probe last, free recall analog is used as a control against which the other probe word positions are compared. The starred items are the probed positions themselves.

\section{Discussion}

There were no important differences in LTS. In STS the best recall came when the probed word was in the ninth position (the fourth from the end, bottom right panel of Figure 3). This effect is entirely consistent with Experiment I and is interpreted as evidence for the hypothesis that retrieval from STS is improved by recalling from STS in the presentation order. The finding is somewhat clouded by the fact that the existence of the probe word was comparable to a mandatory one-word postlist reading task. This forced processing prior to recall appears to have produced overall reduction in STS recall relative to Experiment I.

The results of Experiment II clarify an issue raised in the interpretation of Experiment I. Specifically, the increased end-of-list recall observed in Experiment I cannot be attributed solely to an adjustment of processing during list presentation. When subjects did not know the output sequence desired until after the presentation of the list, they were still able to retrieve more when using forward-ordered recall for end-of-list items. In short, the "STS" effects are based on retrieval, not storage.

\section{EXPERIMENT III}

In Experiment III the retrieval of information from STS was explored further. A modified Peterson and Peterson (1959) task was used to test the hypothesis, 
suggested by the results of the first two experiments, that the best order of retrieval from STS is the order of presentation.

\section{Method}

Subjects. Sixteen students from the same source as previously used participated.

Procedure. Sequences of three high-frequency (A and AA, Thorndike-Lorge) monosyllabic nouns, numbered " 1 ," " 2 ," and " 3 ," were presented one at a time for $1 \mathrm{sec}$ each on a memory drum. These main sequences were followed by a postlist reading task of $0,2,6$, or 10 words. The postlist words were presented in pairs at a $1-\mathrm{sec} /$ pair rate and were intended to displace progressively more of STS. After the postlist words, retrieval was cued by the numbers corresponding to the original words. For instance, " $3,2,1$ " would always signal retrieval in the reverse order. In this way, all six possible orders of retrieving the three words were incorporated into the experiment. For each level of the postlist words variable, there were four forward-cued lists, four backward-cued lists, and four lists representing the four remaining nonserial retrieval orders. This design was preferred over an orthogonal one (where each retrieval order is equally frequent) to obtain the most data from the retrieval orders of greatest interest: forward-and backward-cued recall. Cuing was paced at the original rate of presentation $(1 \mathrm{sec} /$ item), and all recall was counted, so long as it occurred prior to a buzzer which was sounded $1 \mathrm{sec}$ after the last cue was given. The buzzer was intended to prevent the subject from using extra time to manage retrieval. Subjects were then given a second opportunity to recall the sequence uncued in the original order. They were to indicate items they could not recall by saying "blank" where those items occurred. In sum, in this experiment position-cued and uncued recall were studied as a function of order of retrieval and number of postlist words, which were both varied within subjects.

\section{Results}

Figure 4 represents the percentage of total cued recall (responding correctly as cued to all three positions on the task) for each postlist task. An analysis of variance was carried out on the total recall, with order of recall and postlist task as within-subjects variables. A Replications factor (four lists of each type were given) was nested within the two variables and, therefore, interactions with it were used to compose the error term. In general, recall decreased sharply with the increased number of postlist words $[\mathrm{F}(3,36)=79.42, \mathrm{MSe}=.25]$. Overall, the three types of recall orders produced consistent differences $[\mathrm{F}(2,36)=14.23, \mathrm{MSe}=.25]$. The interaction of Orders by Tasks was also significant $[F(6,36)=4.64, \mathrm{MSe}=.25]$. A Newman-Keuls analysis was performed to test the differences in performance at each postlist task for the three types of recall order. Recall in the forward-order recall condition was superior to the reverse and nonserial orders for the no- and twoword postlist tasks $(\mathrm{p}<.05)$, while the reverse and nonserial orders did not differ reliably from each other $(\mathrm{p}>.05)$. For the 6- and 10-word postlist tasks, there were no differences among the three orders of recall $(p>.05)$. As the number of postlist words increases, group differences decrease, suggesting that the effects of order of recall are specific to STS.

Examination of recall for each of the nonserial orders represented (not shown) reveals a correspondence between performance and the first position to be recalled. With no postlist task, performance is high for

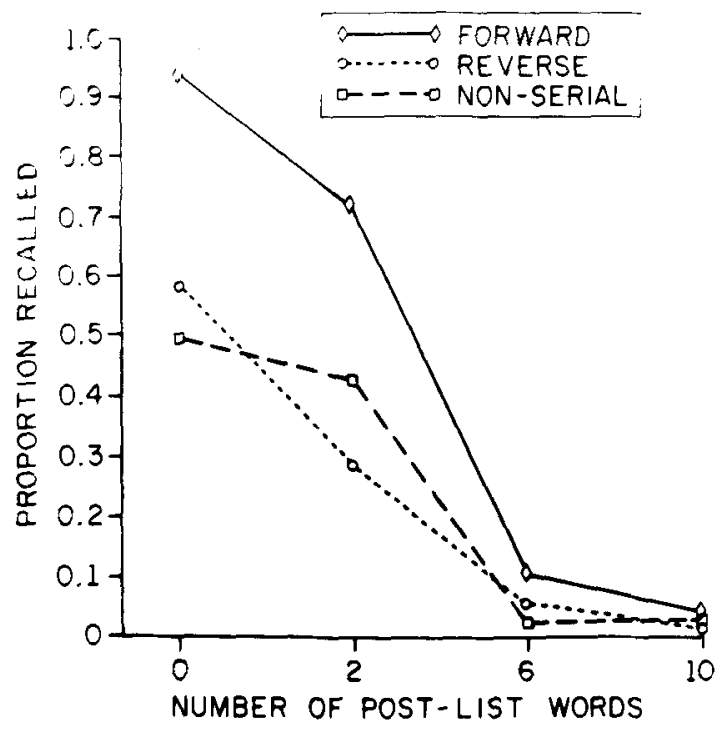

Figure 4. Total sequence recall as a function of number of postlist words for forward-cued, backward-cued, and combined nonserial retrieval orders for Experiment III.

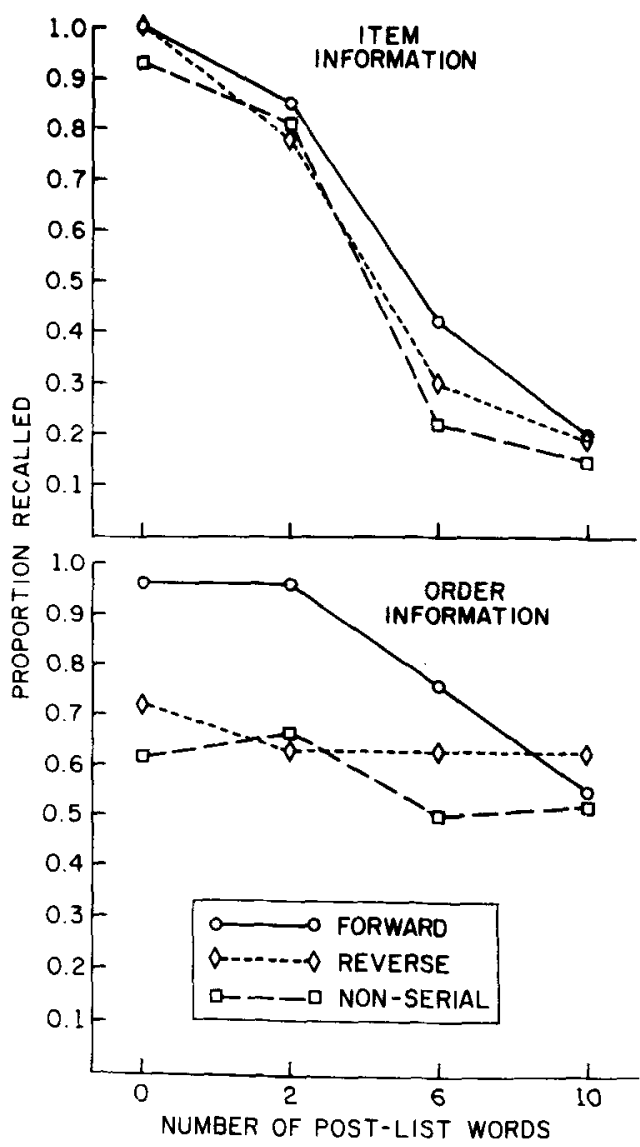

Figure 5. Item (upper panel) and order recall (lower panel) as a function of number of postlist words for forward-cued, backward-cued, and combined nonserial retrieval orders for Experiment III. 
sequences that start with the first position, intermediate for sequences that start with the last position, and low for sequences that start with the middle position.

The recall data, scored separately for order and item information, are represented in the top and bottom panels of Figure 5, respectively. Item recall was based directly on scoring which credited all recalls regardless of order. Order recall was derived from item scoring and "item-plus-order" scoring of the cued recall data, which credited an item only if it was recalled as cued from its originally presented position. Assuming that the probability of recalling item-plus-order is the product of item recall probability and order recall probability, then order recall probability ${ }^{\circ}$ is the item-plus-order probability divided by item recall probability. Essentially, then, the order probability is the conditional probability of recalling an item in the cued position, given it was recalled at all. The data in Figure 5 show that order, and not item, information was differentially affected in this experiment. The converging pattern, seen earlier in the total sequence correct measure (Figure 4), is clearly evident in the order information (lower panel) curves, but not in the item information (upper panel) curves.

\section{Discussion}

The finding that overall performance was best if recall was begun with the first word presented suggests that items are stored quasi-serially in STS. When fast probing of recall is used and a recall other than the original order of presentation is required, the drop in the level of performance may be due to the additional time it takes to access the items held in STS. This conclusion is supported by the data, in that the locus of the effect is in order and not item retention.

In addition to the main hypothesis, this experiment illustrates the methodological isolation of STS and LTS effects through the utilization of a postlist task with a typical short-term memory (STM) procedure. This use and interpretation of a postlist task can be contrasted with that of Keppel and Underwood (1962) in their experiment on proactive interference in STM using a similar procedure. They found that, as the duration of the postlist arithmetic task increased, so did the effects of proactive interference. They interpreted the effect as one based in STM. The standard graphic format for this task presents recall on the ordinate and duration of postlist task (or number of postlist words in the present modification) on the abscissa. Experimental conditions are represented as separate curves. The present analysis interprets a diverging pattern (differences increase with increasing postlist activity) as reflecting effects on LTS coding and a converging pattern (differences only appear with minimal postlist processing) as reflecting STS. When the curves diverge, the experimental effects are increasing with increasing displacement of items from STS and, therefore, with a proportionate increase in the contribution of LTS. When the curves converge, then, experimental effects are reduced as the influence of STS on recall is reduced. Keppel and Underwood (1962) found a diverging pattern with proactive interference (PI) as a variable. Hence, according to the present analysis, the effect of PI was on LTS. This analysis is similar to that of Craik and Birtwistle (1971). In contrast to the diverging pattern associated with PI, the converging pattern in the present experiment reflected an STS effect.

\section{EXPERIMENT IV}

The fourth and final experiment was conducted to elucidate the different roles of the order of recall and the recall of order information on LTS as well as on STS. Single-trial free recall does not require and does not encourage assessment of the retention of order information. Tasks which require the retention of order information typically do so by constraining the subject to recall in order.

In everyday life the importance of retaining order information in LTS is illustrated by the correct procedure for boiling an egg without cracking it: One must remember that the egg is to be put in before heating the water. If one does it backward, a cracked egg is sure to result. In the laboratory, investigators such as Aaronson (1974) are beginning to analyze serial recall for order information, as well as item information. This approach has proven fruitful in that some variables, such as temporal grouping (Ryan, Note 1), can be shown to affect order information but not item information. Similarly, in Experiment III of the present series, retrieval order was shown to affect the retention of order information and not item information in STS.

Accordingly, an associated purpose of the present experiment was to develop a task which combines the advantages of free recall and serial recall. Free recall typically begins with end-of-list items. The fact that STS output occurs first is both necessary and efficient, since any other sequence of recall would displace STS items prior to recall.

In all but rather short lists, serial recall, by instruction, precludes recalling end-of-list items first. Therefore, the exact contribution of STS to the serial position curve is unclear. On the other hand, the serial recall task has the advantage of incorporating the retention of order information, which is an important component of everyday information processing.

The modified recall task used in this experiment tests order and item information, as does serial recall, but does so in a way which permits the outputting of STS first, as does free recall. The modified recall condition required subjects to retain order information, but allowed them to recall the items in any order they desired.

To summarize, then, the free recall condition of Experiment I was contrasted with serial recall and a third "modified" recall. While there have been many experiments comparing free and serial recall, such as those of Jahnke (1965) and Bruder (1970), and while the modified procedure has been used by others, such 
as Talland (1968), they have not been compared within the same experiment; nor have they been subjected to separate analyses of STS and LTS effects.

\section{Method}

Subjects. Sixty students from the previously described source were assigned unsystematically to one of three recall instruction groups.

Procedure. The procedure was identical to that used in Experiment I, except for the recall instructions. The free recall control data from Experiment I were used again. The serial recall group was instructed to recall the list in the order it was presented. These subjects were instructed to say "blank" and to draw a horizontal line on their response card to denote words in positions which they were unable to recall. Serial recall of a list as long as 12 words is extremely demanding. This difficulty level is evidenced by the fact that five subjects given this task appeared to abandon the instruction to recall in order, and, on a majority of their lists with no postlist task, they began their recall with one of the last three words in the list. Therefore, these five subjects were replaced.

In the modified recall condition, the response card contained 12 lines. The subjects were told to recall the words in any order they liked, but to record them on the lines corresponding to their original positions.

In the $1-\mathrm{min}$ recall interval, all subjects said the words as they wrote them on response cards. The experimenter kept track of both the order in which the words were spoken and the order in which they were written. Each subject was shown 12 lists, a random half of which were followed by a six-word postlist reading task.

\section{Results}

The data for this experiment were scored for both item and order information.

Item information. Item information is defined as the simple probability that an item is recalled. In Figure 6 item information is plotted as a function of original list serial position. In the left panel the curves are for lists followed by a postlist reading task; hence, they represent largely the LTS component. On the right are curves for lists not followed by a postlist reading task; hence,
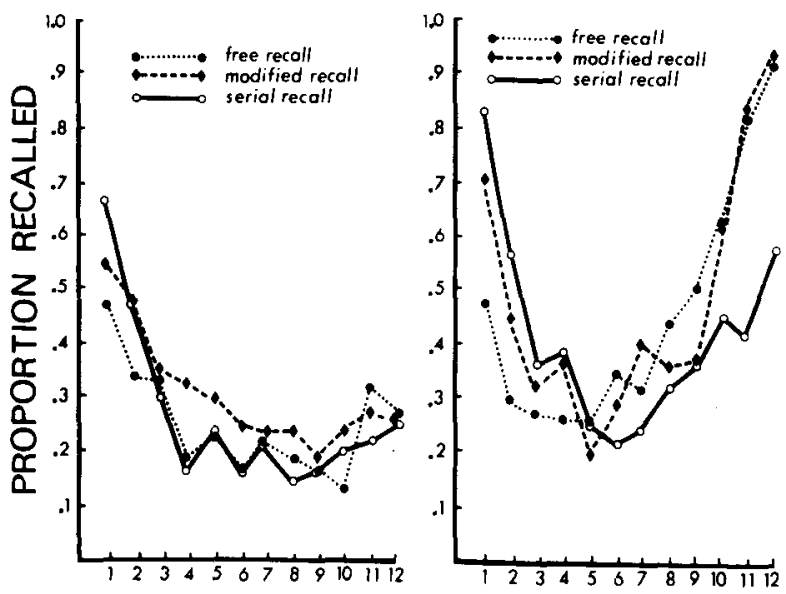

INPUT POSITION

Figure 6. Serial position curves for item recall with a postlist reading task (left) and without (right) in Experiment IV. they include contributions from both LTS and STS. Comparing the right panel to the left, it is clear that the postlist task did eliminate the recency (STS) portion.

Analyses of variance on the recall data were performed separately for the first, second, and third parts of the lists and for lists with and without a postlist task. With a postlist task, there were no consistent effects of recall type ("conditions") except for an interaction of Conditions by Input Position at the beginning of the list $[\mathrm{F}(6,171)=2.61, \mathrm{MSe}=1.30]$. Free recall starts with a lower primacy peak than serial and modified recall. Similarly, in lists without a postlist task, free recall shows a consistently lower primacy effect, which is manifest in a significant effect of Conditions $[F(6,171)=2.49, \mathrm{MSe}=1.21]$. At the end of the list with no postlist task, the serial recall recency effect was lower than those of both free recall and modified recall conditions $[F(2,57)=38.24$, MSe $=1.87]$. In short, as is frequently observed, free recall has a higher recency peak and serial recall a higher primacy peak. In contrast, modified recall shares the best of both worlds. Item recall increases at the beginning, as it does for serial recall, and it also increases at the end, as it does for free recall.

Order information. Two measures of order information were employed. The first of these, the "absolute" measure, was also used in Experiment III and is defined as the conditional probability of recalling an item in the correct position, given that the item is recalled. To calculate the absolute measure, one simply divides the probability of recalling an item in the correct position by the probability of recalling an item, regardless of its position in recall. Since it makes sense to score absolute order information only for conditions in which the subject was instructed to recall order information, this measure is appropriate only for serial and modified recall.

In Figure 7 this absolute measure of order information is applied to both the serial and modified recall conditions, for lists with (top panel) and without (lower panel) a postlist reading task. For the modified condition, this measure was based on the order used in written recall. (For serial recall, written and spoken orders were, or course, the same.) In both panels there is no clear difference in the beginning portion of the list. Differences appear only at the end, where modified recall shows a considerable increment. For serial recall the absolute measure goes to zero at the end of the list, since no subject ever recalled the entire list in order or was able to keep exact track of the number of early items missed. In contrast, subjects in the modified condition did not have to keep track, but were able to use the card and the end of the list as a kind of anchor. It would seem, then, that for modified recall the beginning and end of the list serve as anchors to retain order information, while for serial recall, only the beginning of the list serves this function.

The absolute measure of order information is not an 


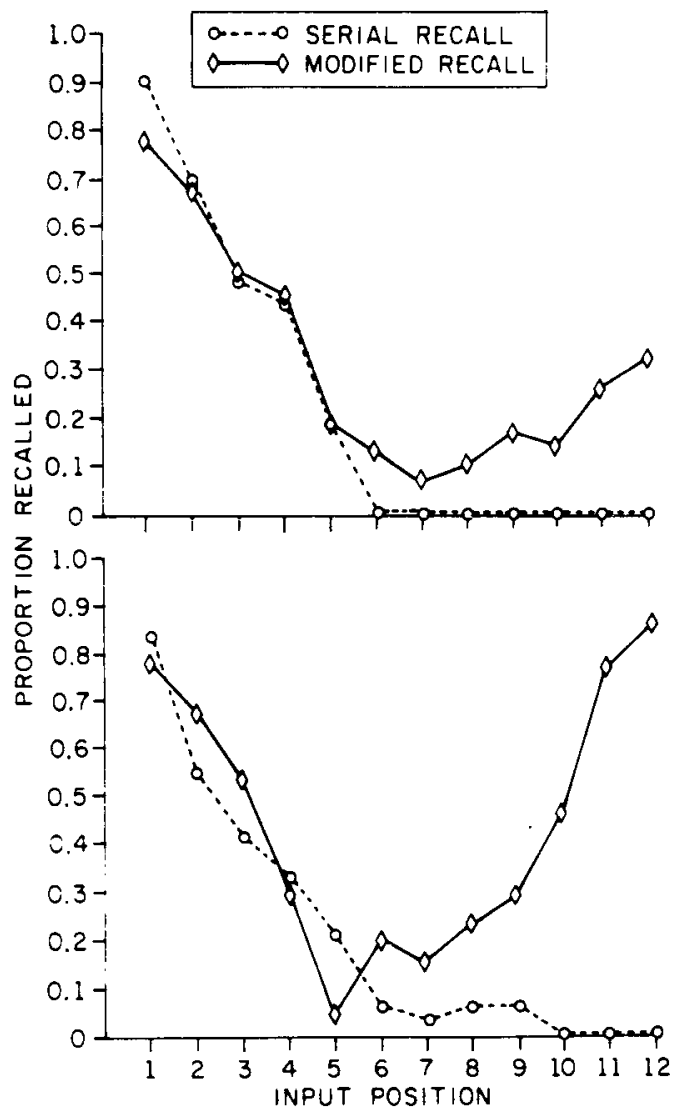

Figure 7. Serial position curves for recall of absolute order information with a postlist (top) and without (bottom) in Experiment IV.

ideal index. Its use depends in part on the subject being able to keep a count of missed items. If this count is off even slightly, the remaining items do not contribute to the measure, even though they may, in fact, be a string of consecutive items. In a long list, such as those used in this experiment, it is probably unrealistic to expect this count to be accurate. Parenthetically, it should be noted that this expectation is appropriate for short lists, such as were used in Experiment III. A second shortcoming of the absolute measure of order information is that it is applicable only to modified and serial recall.

Because of these shortcomings, another measure, the "transitional" measure of order information, was devised. The transitional measure is defined for lists in which an item $n$ and item $n+1$ have been recalled as the probability of recalling item $n$ and $n+1$ in order. This measure reflects the first order sequential constraints in the output sequence and can be used whether or not the subject was instructed to recall in order. Indeed, the measure was applied to free recall and to both the written and spoken order of modified recall, although the subject was instructed to be correct for only the written order.

Figure 8 contains the serial position curves using the transitional measure of order information. In the upper panel the lists were followed by a postlist reading task; in the lower panel they were not. No systematic trends appear in the data except at the beginning and end of the list. The transitional order information contained in modified recall as spoken was about equal to the order information contained in free recall. In other words, if one heard only the modified recall, one might confuse its ordering with free recall. These two conditions show moderate order information overall, and not much, if any, serial position effect. In contrast, modified (written) and serial recall both showed high transitional order information at the beginning of the list. At the end of the list, there was slightly more order information in serial recall, regardless of whether or not there was a postlist task. When there was no task, the written order

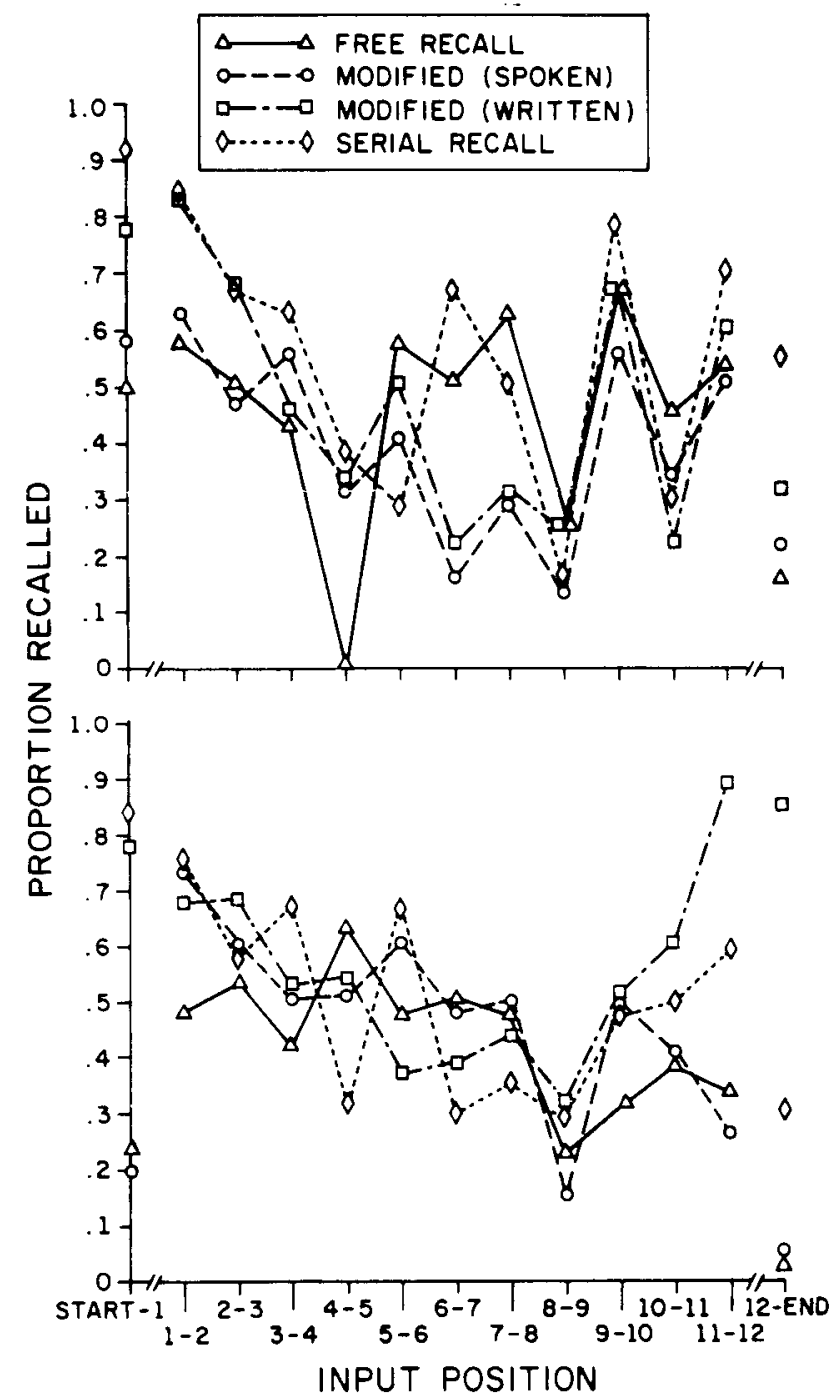

Figure 8. Serial position curves for recall of transitional order information with a postlist reading task (top) and without (bottom) in Experiment IV. The unconnected data points at the beginning and end of the lists represent the proportion of recalls which were begun with the item from the first input position, given that it was recalled at all, and ended with the last input position, given that it was recalled. 
of modified recall was substantially higher than for all other conditions. Since this effect was eliminated by the postlist task, it is undoubtedly associated with STS.

\section{Discussion}

This experiment successfully demonstrated the use of the modified recall procedure to show distinct STS and LTS effects and to dissociate the recall of order information from the constraint to recall in order. If one compares the serial position curves in the two panels of Figure 6 (with and without a postlist task), one finds that for modified recall, like for free recall, the postlist task eliminates only the end-of-list (recency) recall. This finding suggests that it is possible to associate end-of-list effects with STS without using the postlist task (Raymond, 1969) procedure. In serial recall, however, the postlist task reduces recall from both the beginning and end of the list. This finding indicates that STS contributions to serial recall are not restricted to the end of the list. Observations of the subjects' behaviors supports this interpretation, in that subjects were observed to vocalize early items quietly during presentation of later items. This recycling would result in some early items being in STS at the beginning of recall. It would also give those items more time in working memory to be coded into LTS. Therefore, it is not surprising that with a postlist task early items retain some advantage when compared to free recall. This LTS advantage appears restricted to the first item or two and is not unlike the LTS advantage observed for the marked words in Experiment I (see Figure 1). In serial recall, as well as in the Experiment I procedure, the subject appears to generate self-instructions to give priority to coding the word with which recall is to start. To summarize, the modified recall serial position curve without a postlist task is directly interpretable, as is that of free recall, in terms of LTS and STS effects. These effects are concentrated at the beginning and the end of the list, respectively. Serial recall is not so easily interpretable.

The second main point is that the modified task permitted the assessment of order information. In fact, it enabled the subjects to show more knowledge about order information than in serial recall at the end of the list (see Figures 7 and 8 ).

Finally, there appears to be a slight interaction between the requirement to recall order information (as in serial and modified recall) and the coding of item information in LTS. For serial recall, as was discussed, this effect is concentrated at the very beginning of the list and may be understood as reflecting a selfinstruction to remember the first word or words in order to start recall. In modified recall the LTS advantage over free recall is smaller but persists through the first half of the list. It suggests that the task requirement to code order information induces a somewhat more efficient manner of coding item information in LTS.

\section{CONCLUSIONS}

The first three experiments all contribute to the substantiation of the hypothesis that the best order of retrieving information from STS is to start with the original order of presentation. Moreover, in agreement with Craik (1968), who used several methods of estimating STS, including Waugh and Norman's (1965), it is suggested that the storage capacity of STS is about three to four words, slightly greater than the 2.7 estimate of Glanzer (Note 2) or the 2.3 of Glanzer (1972) and considerably less than the "magical number 7" of Miller (1956). Glanzer's underestimate appears to have resulted from the use of inefficient retrieval orders by his free recall subjects. For some unknown reason, in free recall unsystematic orders of recall predominate, although recall does begin with items from the end portion of the list. Indeed, in Experiment I almost half of the free recall protocols began with the last word in the list. Interestingly, an improved retrieval scheme is adopted spontaneously by subjects given temporally grouped lists (Gianutsos, 1972). In this condition subjects recall the last temporally grouped items in order. It is interest. ing that free recall leads to a less than optimal order of retrieval. At this point, the evidence for the first conclusion is strong: namely, that for improving STS recall the critical factor is recalling or retrieving in order. The only qualification is that this recall should be started immediately at the end of list presentation and from within the span of STS.

The results of the first three experiments further our understanding of STS by (1) demonstrating that ordered recall is superior to free recall, (2) showing that recall is maximized when the order begins with the first items presented within the span of STS, and (3) providing evidence which enables us to revise our estimate of the capacity of STS.

The results of the fourth experiment, taken together with these findings, reaffirm our confidence in asserting that the knowledge of order information should be distinguished from the order of recall. While for STS serial recall does produce the most recall of both order and item information (Experiment III), it does not for LTS (Experiment IV). For the LTS primacy peak, more item and order information is produced by the modified recall procedure, which permits the subject to communicate knowledge of order information without attempting serial recall. In supraspan memory tasks the recall strategy suggested by these studies would, therefore, be as follows: (1) First, recall items from STS in order, and (2) then recall other items in a manner which includes information about their original order, as in modified 
recall, but which does not require serial recall. In a few words, then, the recall of order may be synonymous with the order of recall for STS but not for LTS.

\section{REFERENCE NOTES}

1. Ryan, J. Grouping and short-term memory. Unpublished doctoral dissertation, University of Cambridge, September 1967.

2. Glanzer, M. Paper presented to the Eastern Verbal Investigators' League, Waltham, Massachusetts, April 1971.

\section{REFERENCES}

Aaronson, D. Stimulus factors and listening strategies in auditory memory: A theoretical analysis. Cognitive Psychology, 1974, 6, 108-132.

BRUDER, G. A. Analysis of differences between free and serial recall. Joumal of Experimental Psychology, 1970, 83, 232-237.

CRAIK, F. I. M. Two components in free recall. Journal of Verbal Learning and Verbal Behavior, 1968, 7, 996-1004.

CRAir, F. I. M., \& Birtwisthe, J. Proactive inhibition in free recall. Joumal of Experimental Psychology, 1971, 91, 120-128.

Craik, F. I. M., \& Levy, B. A. Semantic and acoustic information in primacy memory. Journal of Experimental Psychology, 1970, 86, 77.82.

Gianutsos, R. Free recall of grouped words (Doctoral Dissertation, New York University, 1970). Dissertation Abstracts International, 1971, 31, 7624B-7625B. (University Microfilms No. 71-15, 388).

GinNuTsos, R. Free recall of grouped words. Journal of Experimental Psychology, 1972, 95, 419-428.

Glanzer, M. Storage mechanisms in recall. In G. Bower (Ed.), The psychology of leaming and motrivation: Advances in research and theory (Vol. 5). New York: Academic Press, 1972. Pp. 129-193.

Glanzer, M., Gunutsos, R., \& Dubin, S. The removal of items from short-term storage. Joumal of Verbal Leaming and Verbal Behavior, 1969, 8, 435-447.
JAHNKE, J. C. Supplementary report: Primacy and recency effects in serial position curves of free recall. Journal of Experimental Psychology, 1965, 70, 130-132.

Keppel, G., \& Underwood, B. Proactive inhibition in shortterm retention of single items. Journal of Verbal Learning and Verbal Behavior, 1962, 1, 153-161.

Miller, G. A. The magical number 7 plus-or-minus two. Psychological Review, 1956, 63, 81-97.

Peterson, L. R., \& Peterson, M. J. Short-term retention of individual verbal items. Journal of Experimental Psychology, 1959, 58, 193-198.

PosNer, M. I. Rate of presentation and order of recall in immediate memory. British Journal of Psychology, 1964. 55, 303-306.

Postman, L. Verbal learning and memory. Annual Review of Psychology, 1975, 26, 291-335.

RAymond, B. Short-term and long-term storage in free recall. Joumal of Verbal Learning and Verbal Behavior, $1969,8,567-574$.

ShIfFrin, R. M. Memory search. In D. A. Norman (Ed.), Models of human memory. New York: Academic Press, 1970. Pp. 375-447.

TAlland, G. A. Age and the span of immediate recall. In G. A. Talland (Ed.), Human aging and behavior. New York: Academic Press, 1968. Pp. 93-130.

Tulving, E., \& ARB UCKIE, T. Y. Sources of intratrial interference in the immediate recall of paired associates. Journal of Verbal Learning and Verbal Behavior, 1963. $1,321-334$

Tulving, E., \& Colotra, V. Free recall of trilingual lists. Cognitive Psychology, 1970, 1, 86-98.

Watkins, M. J., \& Watkins, O. C. Processing of recency items for free recall. Joumal of Experimental Psychology, 1974, 102, 488-493.

Waugh, N. C., \& Norman, D. A. Primary memory. Psychological Review. 1965. 72, 89-104.

(Received for publication November 14, 1975; revision accepted March $16,1976$. .) 